\title{
Caracterização da organização do processo ofensivo em pólo aquático feminino de elite
}

\author{
S. Canossa, J. Garganta, M. Lloret, F. Argudo, R. Fernandes
}

No presente estudo procedeu-se à caracterização da organização do processo ofensivo em Pólo Aquático feminino de elite a partir da observação de 442 sequências ofensivas de 8 jogos realizadas pelas principais equipas participantes num Campeonato Europeu. Para o feito, foram apuradas 17 variáveis tácticotécnicas inerentes à gestão do espaço de jogo, à posição e à participação dos jogadores, à organização táctica e aos métodos de jogo utilizados, bem como à eficácia das acções empreendidas. Os resultados obtidos permitem concluir que: (i) o ataque posicional é o método de jogo predominante no processo ofensivo, tendo por oposição a defesa mista com flutuação; (ii) o contra-ataque constitui-se como o método de jogo mais eficaz; (iii) o processo ofensivo inicia-se através da recuperação da posse da bola por antecipação e defesa da guarda-redes, predominando a utilização de um primeiro passe de alcance longo efectuado para o corredor direito; (iv) as formas preferenciais de finalização são o remate directo da primeira linha ofensiva, as desmarcações assistidas e as situações de superioridade numérica temporal; $(v)$ no conjunto das sequências ofensivas predominam as que não chegam a esgotar os 35 s regulamentares; (vi) a eficácia das equipas correlaciona-se com os meios tácticos adoptados, destacando-se o remate directo com origem na primeira linha ofensiva, a desmarcação assistida e as situações de superioridade numérica temporal.

Palavras-chave: pólo Aquático, equipas femininas, análise do jogo, eficácia ofensiva

Submetido: 17.03.2009| Aceite: 24.04.2009

Sofia Canossa, Júlio Garganta e Ricardo Fernandes. Centro de Investigação, Formação, Inovação e Intervenção em Desporto, Universidade do Porto.

Mário Lloret. Docente do Instituto Nacional de Educación Física de Cataluña, Universidade de Barcelona.

Francisco Argudo. Docente da Facultad de Formación de Profesorado y Educación, Univ. Autónoma de Madrid.

Endereço para correspondência: Prof. Dr. Ricardo Fernandes, Faculdade de Desporto, Universidade do Porto, Rua Dr. Plácido Costa, 91, 4200-450 Porto. E-mail: ricfer@fade.up.pt 


\section{Attacking process characterization of elite water polo female teams}

The purpose of the present study was to analyze the attacking tasks and tactical organization of elite Women's Water Polo. The sample consisted of 442 attack sequences of 8 games played by the top teams in a European Championship. Seventeen variables were analyzed according to the position and player's participation, tactical organization and playing styles, as well as the efficacy of actions performed. The results from this study indicate that positional attack was the predominant performance factor in the attacking process. To this occurrence, the mixed floating defense was identified as the most frequent opposition. The counterattack proved to be the most efficient strategy. The attacking process frequently started by ball recovering, in anticipation, and by the defense of the goal-keeper in the $2 \mathrm{~m}$ zone. In central path, a first long-range pass to the right wing predominated. Teams preferred spontaneous shot on goal supported by assisted displacements, and extra player man offence situations. In general, the attacking sequences, do not take longer than 35 s to be developed.) Teams efficiency emerged related to the tactical means adopted, namely the spontaneous shot at goal on the front line and numerical superiority of players in attacking game situations.

Key words: water-polo, female teams, match analysis, attacking efficacy

Embora o Pólo Aquático tenha sido a segunda modalidade desportiva colectiva a ser implementada em Portugal (Sarmento, 1989) é uma disciplina desportiva ainda pouco estudada (Carreiro 1992; Pinto, Carvalho, \& Saraiva, 1989). Esta escassez de investigação, e de consequente literatura especializada, não se restringe, contudo, ao espaço nacional português. A este propósito, o Director da Escola Nacional de Treinadores da Real Federação Espanhola de Natação lamentava a escassez de literatura dedicada a esta modalidade, apesar da própria equipa masculina espanhola ter sido finalista dos Jogos Olímpicos de Barcelona'1992 e Campeã Olímpica em Atlanta'1996 (Lloret, 1998).

Em Portugal, no que se refere especificamente ao Pólo Aquático feminino, a Selecção Nacional Absoluta estreou-se no Campeonato Europeu (final A) em Viena de Áustria (1995), conseguindo uma nova participação na principal competição da Europa em 1997 na cidade de Sevilha. Embora o desenvolvimento e afirmação do Pólo Aquático em Portugal seja uma realidade, nomeadamente pelo incremento do número de praticantes nos escalões de formação (Canossa, Fernandes, Carmo, Andrade, \& Soares, 2007; Ribeiro, 2005), verifica-se que a equipa feminina Portuguesa não alcança o apuramento para a fase final de um Campeonato da Europa (ou competição similar) há mais de uma década. Poder-se-iam alvitrar algumas explicações para a tímida expressão competitiva das equipas Portuguesas 
de Pólo Aquático no quadro das competições internacionais. Porém, todas elas, directa ou indirectamente, estariam reféns da escassez de estudos relativos a modalidade desportiva. Estamos convictos que sem um conhecimento objectivo da prestação das formações Portuguesas, dificilmente se poderá delinear estratégias ajustadas e consistentes para se atingir níveis de desempenho mais elevados (Canossa, 2001).

No presente estudo procura-se descrever o modelo de jogo de Pólo Aquático feminino de elite, considerando que este opera como um instrumento de relação orientada entre a realidade existente e aquela que desejamos provocar (Adelino, 1987). Esta linha de pesquisa parte da premissa da necessidade de estabelecer referenciais de actuação no sentido da excelência. Deste modo, estudou-se a fase ofensiva do jogo, dado que é na elaboração do ataque que se encontram as maiores dificuldades do Pólo Aquático português no confronto com níveis de jogo superiores (Carreiro, 1992; Sarmento, 1991).

A fim de se poder contribuir para o desenvolvimento da Selecção Nacional feminina no que concerne à organização ofensiva, entendeu-se que se deveria observar, fundamentalmente, o desempenho das equipas de elite nessa fase do jogo para que, através da sua esquematização, se consiga configurar um modelo representador do processo ofensivo. Segundo Garganta (1997), a observação e análise das competições, para além de possibilitar um melhor conhecimento sobre a realidade do jogo, permite avaliar, organizar e regular os processos de ensino, de treino e de competição. Neste sentido, os Campeonatos do Mundo e da Europa são momentos cruciais para a definição de modelos e detecção de tendências evolutivas do jogo (Pinto \& Garganta, 1986). Porém, no domínio dos jogos desportivos colectivos, os estudos centrados na dimensão táctica são expostos a algumas dificuldades e limitações, nomeadamente no que se refere ao tipo e à quantidade de indicadores a considerar como representativos das fases e dos momentos do jogo (Bayer, 1994; Castelo, 1994; Egaña, 2000; Gréhaigne, 1992; Silva, 2000). Para além disso, constata-se que o tratamento dos dados recolhidos a partir de tais raramente tem permitido obter informação relevante a propósito da organização táctica dos jogadores e das equipas (Argudo \& Lloret, 1994; Argudo, 2000; Egaña, 2000; Garganta, 1997; Silva, 2000).

Os objectivos do presente estudo consistem em: (i) caracterizar o modelo de jogo ofensivo do Pólo Aquático feminino de elite através da observação e análise do comportamento de variáveis táctico-técnicas das três equipas melhor classificadas numa competição internacional de elevado nível desportivo (Campeonato 
Europeu) e (ii) evidenciar os indicadores de eficácia ofensiva que se afiguram relacionados com o sucesso das equipas.

Deste modo, através da configuração do modelo de jogo ofensivo do Pólo Aquático de elite visa-se contribuir para a clarificação de indicadores de sucesso, de modo a viabilizar a reflexão sobre o ensino, o treino e a competição no âmbito desta modalidade desportiva.

\section{Metodologia}

No estudo presente, procurou-se identificar o tipo e a eficácia dos métodos de jogo mais frequentemente utilizados num Campeonato Europeu de Pólo Aquático feminino. Para tal, foram descritas as acções ofensivas indutoras de desequilíbrios na estrutura defensiva adversária, assim como as formas preferenciais de iniciar, desenvolver e concluir o processo ofensivo.

\section{Amostra}

A amostra integra 442 sequências ofensivas, extraídas das oito partidas realizadas pelas equipas melhor classificadas: a equipa Campeã da Europa (Eq1), a equipa Vice-Campeã (Eq2) e a equipa $3^{\text {a }}$ classificada (Eq3). Os jogos analisados foram os disputados entre estas equipas nos seguintes momentos (cf. Quadro 1): (i) fases preliminares de apuramento; (ii) quartos de final (entre as três primeiras equipas e respectivas oponentes) e (iii) finais (entre as duas primeiras equipas e entre a Eq3 e a oponente na disputa do terceiro lugar).

Quadro 1. Jogos de Pólo Aquático feminino observados no presente estudo

\begin{tabular}{|c|c|c|c|}
\hline $\begin{array}{c}\text { Fases do } \\
\text { Campeonato }\end{array}$ & Jogos observados & $\begin{array}{c}\text { Sequências por equipa } \\
\text { observada (n) }\end{array}$ & $\begin{array}{c}\text { Sequências } \\
\text { observadas por jogo } \\
\text { (n) }\end{array}$ \\
\hline Preliminar & $\mathrm{Eq} 1 \times \mathrm{Eq} 2$ & $33-35$ & 68 \\
\hline Preliminar & $\mathrm{Eq1} \times \mathrm{Eq} 3$ & $43-42$ & 85 \\
\hline Preliminar & $\mathrm{Eq} 3 \times \mathrm{Eq} 2$ & $41-38$ & 79 \\
\hline Preliminar & Eq2 $\times$ oponente & 33 & 33 \\
\hline Quarto de final & Eq3 $\times$ oponente & 35 & 35 \\
\hline Quarto de final & oponente x Eq1 & 41 & 41 \\
\hline $3^{\circ}$ e $4^{\circ}$ lugares & Eq3 $\times$ oponente & 35 & 35 \\
\hline Final & $\mathrm{Eq} 1 \times \mathrm{Eq} 2$ & $34-32$ & 66 \\
\hline Total & $\begin{array}{l}8 \text { jogos / } 12 \\
\text { observações }\end{array}$ & $\begin{array}{c}\text { Eq1 (151), Eq2 (138) e } \\
\text { Eq3 (153) }\end{array}$ & 442 \\
\hline
\end{tabular}




\section{Procedimentos}

\section{Modelo conceptual adoptado}

O procedimento de observação e análise adoptado foi construído com base em Garganta (1997). Este autor considera que nos jogos desportivos colectivos, sendo a táctica um constrangimento nuclear, é fundamental que as variáveis de observação e análise do jogo se reportem à organização das equipas durante as fases de jogo, de modo a considerar o modo como as acções de jogo decorrem da relação que se estabelece entre as equipas em confronto.

Neste sentido, considerou-se o desenvolvimento do processo ofensivo de Pólo Aquático à semelhança dos restantes jogos desportivos colectivos, isto é, de acordo com a oposição que se verifica num determinado tipo de organização defensiva, na respectiva relação com os métodos de jogo ofensivo adoptados e com os meios tácticos utilizados preferencialmente no processo ofensivo. Os meios tácticos, métodos de jogo ofensivo e tipos de organização defensiva, permitiram observar o comportamento táctico das jogadoras e equipas no que concerne à operacionalização e à forma de organização do processo (Canossa, 2001).

Com o intuito de seleccionar as variáveis mais representativas, procurou-se sistematizar os constrangimentos típicos de um jogo de Pólo Aquático. Assim, e tendo em conta a especificidade do meio aquático, nomeadamente a sua densidade e ausência de apoios fixos (Lloret, 1994; Lopes, 1985; Sarmento, 1994; Sarmento, 1995), os principais problemas que o jogo coloca aos jogadores são os seguintes: (i) contacto físico com ou sem bola e consequente diminuição da velocidade de deslocamento; (ii) a reduzida criação de incerteza para os adversários; (iii) limitação generalizada de todas as acções táctico-técnicas e (iv) dificuldade na construção de situações de finalização, salientando a necessidade de criar superioridade posicional e numérica.

A partir deste entendimento, foram consideradas para a análise não apenas as acções imediatamente anteriores à marcação do golo, mas também as acções individuais e colectivas empreendidas pelos jogadores e equipas na procura de superioridade (posicional e numérica) face ao adversário.

O movimento global da equipa, empreendido entre a sua baliza e a baliza contrária, desenvolve-se a partir da conquista da bola e termina com a sua perda. Com base na literatura da especialidade (Argudo, 2000; Argudo \& García, 1996; Carreiro, 1992; Lloret, 1994; Lloret, 1998; Lopes, 1985, Pinto, Carvalho \& Saraiva, 1989, Sarmento, 1987; Sarmento \& Magalhães, 1991; Sarmento, 1994; Sarmento, 1995), 
foram considerados três momentos no desenvolvimento da sequência da acção da equipa, relacionando-os com acções individuais e colectivas que, a priori, favorecem o seu êxito: (i) recuperação da posse da bola, provocada por falhas técnicas, remate precipitado de uma determinada posição de jogo ou para uma zona determinada, conquista da posse da bola por intercepção, antecipação e desarme e antecipação da saída para o ataque (posicionar um ou mais jogadores à frente da linha defensiva adversária e efectuar o primeiro passe com precisão e eficácia para o jogador melhor posicionado); (ii) transição defesa/ataque, fomentando um estilo de jogo directo (com o $1^{\circ}$ passe para após o meio campo), assim como o contra-ataque (com vantagem posicional e numérica e conseguir a vantagem posicional ou numérica durante a transição); e (iii) ataque posicional, criando incerteza (realizando fintas e variações de passe e corredores), efectuando penetrações pelo espaço defensivo adversário e assistências, obtendo vantagem posicional e numérica e respeitando o equilíbrio no dispositivo ofensivo criando a dinâmica global da equipa.

\section{Explicitação das variáveis e metodologia da observação}

De acordo com o modelo de observação e análise em Pólo Aquático desenvolvido (Canossa, 2001) foram contempladas as seguintes variáveis: (i) área de aquisição ou recuperação da bola; (ii) número de variações de corredor; (iii) tempo de realização do ataque; (iv) formas de recuperação da posse da bola; (v) primeiro passe; (vi) número de passes; (vii) número de variações de passe; (viii) número de jogadoras; (ix) sequência ofensiva; $(x)$ resultado da sequência; (xi) meios tácticos utilizados no processo ofensivo; (xii) métodos de jogo ofensivo; (xiii) tipos de organização defensiva; (xiv) coeficiente ofensivo de eficácia absoluta (COEA) e (xv) coeficiente ofensivo de eficácia relativa (COER). Estes coeficientes determinaram-se através das seguintes equações:

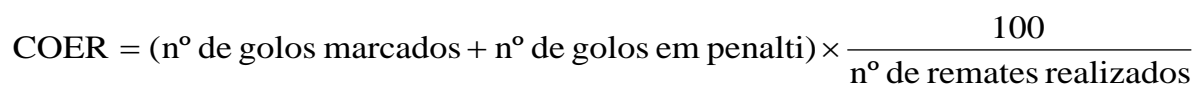

$$
\text { COEA }=\left(n^{\circ} \text { de golos marcados }+n^{\circ} \text { de golos em penalti }\right) \times \frac{100}{n^{\circ} \text { de sequências ofensivas }}
$$

Foi utilizado um campograma de Pólo Aquático de forma a responder às necessidades de uma observação tão objectiva quanto possível, o qual continha a identificação da primeira e segunda linhas ofensivas, bem com as áreas e 
corredores de acção, segundo o referencial ofensivo, delimitados pelas linhas regulamentares do campo de jogo. A recolha dos dados relativos às variáveis seleccionadas decorreu de acordo com quatro momentos de observação e registo, fazendo-se corresponder a cada momento uma ficha de notação manual aglutinando os dados, posteriormente, numa ficha panorâmica de síntese.

\section{Recolha e registo de imagens}

Os jogos foram filmados de um plano superior utilizando duas câmaras de vídeo (Sony VHS), tendo-se recorrido ao método de focagem inicial sobre o centro do terreno para, posteriormente, face à entrada em posse de bola por uma das equipas, se acompanhar a acção de jogo cobrindo todo o meio campo em que esta se desenvolvia (Argudo, 2000). Para a recolha dos dados os jogos foram observados, através de um televisor (Toshiba FST) e de um vídeo gravador (Sony VHS SLV-SE10).

A comissão organizadora do Campeonato da Europa foi detalhadamente informada sobre os procedimentos exploratórios, tendo autorizado a recolha de imagens e seu futuro tratamento.

\section{Procedimentos estatísticos}

A fiabilidade intra-observador foi testada segundo Bellack et al. (1966), tendo-se verificado percentagens de acordos entre 82 e 100\% para as variáveis em estudo. Com o intuito de se analisar os dados recolhidos e se verificar o comportamento das variáveis em estudo, recorreu-se a medidas da estatística descritiva, designadamente a média, o desvio-padrão, a amplitude de variação, a frequência de ocorrência e a respectiva percentagem. Ainda no sentido de se discriminar os indicadores de eficácia ofensivos do jogo, foram utilizados testes de medidas não paramétricas e independentes, nomeadamente o Qui-Quadrado e o Mann Whitney. Utilizou-se, também, o cálculo da correlação de Pearson e da correlação não paramétrica de Kendall's tau $b$.

\section{Resultados}

Da análise realizada, constatou-se que as três equipas estudadas, frequentemente, recuperam a posse da bola na área dos $2 \mathrm{~m}$ do corredor central. Como se pode observar na Figura 1, essa recuperação é materializada, sobretudo, através da antecipação e da defesa da guarda-redes. A única equipa que apresenta valores mais elevados de desarme em vez de ressalto defensivo é a Eq3. 


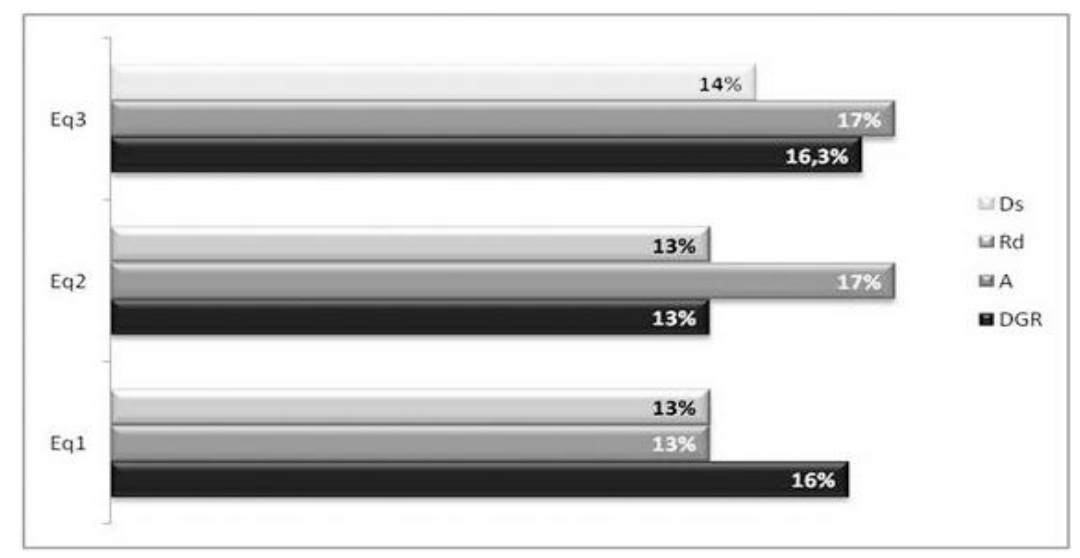

Figura 1. Indicadores preponderantes relativos às formas de recuperação da posse da bola registadas para as equipas em estudo

A: antecipação, DGR: defesa da guarda-redes, Ds: desarme e Rd: ressalto defensivo.

Verificou-se, igualmente, que as equipas analisadas adoptam, preferencialmente, um primeiro passe longo para iniciarem as sequências ofensivas, destacando-se a Eq3 com $73 \%$ de utilização deste tipo de passe. Este passe longo foi frequentemente recepcionado após o meio campo ofensivo, no corredor direito, à excepção da Eq2 que não tem um corredor preferencial para a recepção deste primeiro passe.

Adicionalmente, calculou-se a média de participação directa no processo ofensivo de $4.3 \pm 1.4(M \pm D P)$ jogadoras (incluindo a guarda-redes), tendo-se observado que

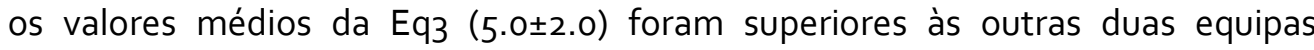
(4.0 \pm 1.0 para a Eq1 e Eq2).

Também se observou que as três formações apresentam o mesmo valor médio do número total de passes por sequência ofensiva $(n=5)$, não se verificando diferenças relativamente ao número de variações do alcance do passe. Na Eq1 e Eq3, verificou-se que as variações de corredor induzidas à bola, através da acção de passe, oscilam entre uma e cinco variações, enquanto na Eq2 se foram entre duas e seis variações.

Na Figura 2 pode-se observar que o método de jogo ofensivo predominante nas três equipas foi o ataque posicional. Contudo, verificou-se que a Eq3 apresentou um total de $27 \%$ de desenvolvimento de sequências ofensivas de desfecho rápido (ataque rápido e contra-ataque), em que 19\% corresponderam ao método de contra-ataque. 


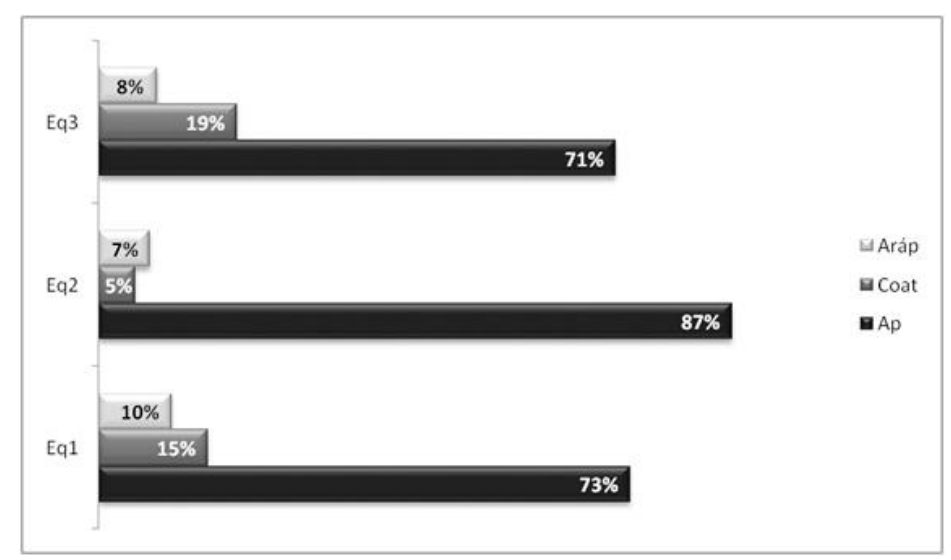

Figura 2. Frequências dos métodos de jogo ofensivo para as formações em estudo Arap: ataque rápido, Coat: contra-ataque e Ap: ataque posicional.

Dos meios tácticos de grupo e colectivos predominantes no ataque posicional, constatou-se que a Eq1 e a Eq2 desenvolveram, preferencialmente, o ataque posicional organizado, sem mudanças dos elementos no dispositivo inicial adoptado, enquanto a Eq3 o desenvolveu com movimentos de entrada e penetração pelo espaço defensivo adversário (cf. Figura 3).

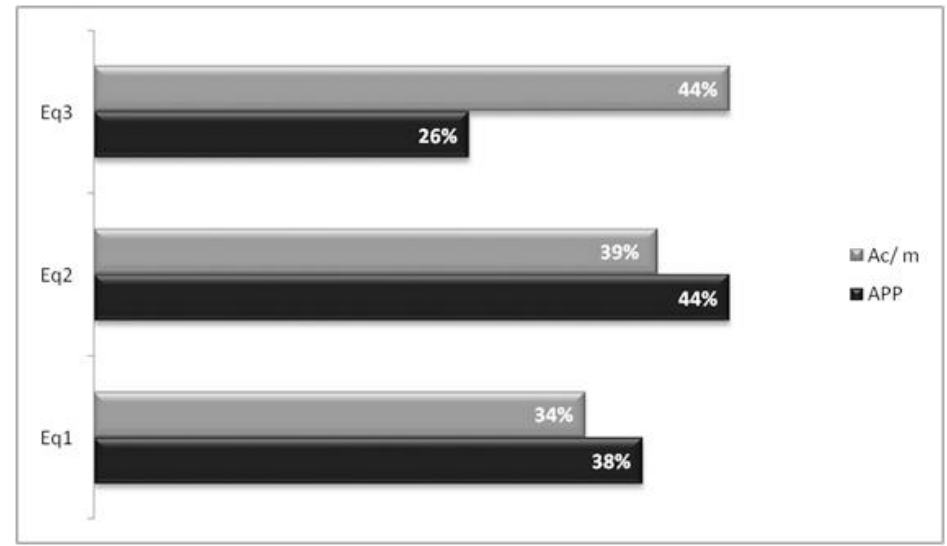

Figura 3. Meios tácticos, de grupo e colectivos, predominantes no ataque posicional relativamente às equipas analisadas

Ac/m: movimentos de entrada e penetração pelo espaço defensivo adversário e APP: ataque posicional organizado

Relativamente à materialização da acção ofensiva, as três formações adoptaram, preferencialmente (frequência de 37\%), o meio táctico individual de remate directo, constatando-se que a Eq1 também optou pelo remate com simulação, tendo este origem na segunda linha ofensiva. 
As movimentações ofensivas entre grupos de jogadoras basearam-se em meios tácticos de grupo ou colectivos como a desmarcação assistida (24\%), com elevada ocorrência na Eq3, bloqueios, reajustes assistidos e assistências da jogadora pivot para as suas colegas posicionadas fora do semicírculo ofensivo $(7,2 \%)$, e, confrontos $1 \times 1$, sem bola, que originaram situações de superioridade numérica.

Estas últimas, tanto foram desenvolvidas de forma posicional pura, fixa, como foram desenvolvidas com mudança dos elementos na estrutura inicial definida. No caso da Eq3, verificou-se uma predominância da alteração do sistema 4:2 para 3:3. O tempo médio despendido pelas equipas para realizar o ataque foi variável, sendo de $21 \pm 11 \mathrm{~s}$, de $35 \pm 3$ s e de $38 \pm 4$ s, respectivamente, para a Eq1, Eq2 e Eq3.

Relativamente ao tipo de oposição recebida pelas equipas estudadas, destacou-se a oposição passiva (que visa a cobertura do centro do campo e a defesa mista com flutuação). Embora a Eq3 se tenha classificado em terceiro lugar, obteve valores superiores neste parâmetro, tanto em termos absolutos como relativos (cf. Quadro 2).

Quadro 2. Coeficientes de eficácia, absolutos e relativos, para as equipas em estudo.

\begin{tabular}{ccc}
\hline & $\begin{array}{c}\text { Coeficiente ofensivo de eficácia } \\
\text { absoluta }\end{array}$ & $\begin{array}{c}\text { Coeficiente ofensivo de eficácia } \\
\text { relativa }\end{array}$ \\
\hline Equipa 1 & $18 \%$ & $27 \%$ \\
Equipa 2 & $19 \%$ & $28 \%$ \\
Equipa 3 & $30 \%$ & $39 \%$ \\
\hline
\end{tabular}

Por último, realçamos os seguintes resultados que consideramos importantes para a configuração do modelo de jogo ofensivo de elite: (i) a acção ofensiva iniciou-se, frequentemente, através da recuperação da posse da bola por antecipação e defesa da guarda-redes (31\%), na área dos $2 \mathrm{~m}$ do corredor central (48\%); (ii) o primeiro passe foi, em percentagem elevada, de alcance longo (58\%) e foi sobretudo efectuado para o corredor direito (50\%); (iii) predomina o ataque posicional como método de jogo (77\%); (iv) o contra-ataque, embora menos frequente (13\%), constitui-se como o método de jogo mais eficaz ( $45 \%$ de eficácia relativa); (v) foram acções tácticas predominantes no desenvolvimento das sequências ofensivas as desmarcações assistidas (14\%) e situações de superioridade numérica (16\%); (vi) o recurso mais frequente das formações, perante a acção de finalização, foi o remate, com origem na primeira linha ofensiva (23\%); (vii) as sequências ofensivas que expressaram um tempo de realização do ataque superior a $35 \mathrm{~s}$ 
revelaram pouca ocorrência (6\%), ou seja, predominaram as que não chegaram a esgotar os 35 s iniciais para o desenvolvimento do processo ofensivo.

\section{Discussão}

O local e a forma de recuperação da posse da bola, bem como o seu primeiro envio no processo ofensivo, podem espelhar opções de organização táctica por parte das diferentes equipas de Pólo Aquático. No presente estudo, os resultados obtidos quanto à predominância da recuperação da bola na área dos $2 \mathrm{~m}$ do corredor central sugerem dois aspectos fundamentais relativos à organização defensiva das equipas analisadas: (i) a opção pelas defesas mistas com flutuação, ludibriando o adversário quanto à linha de passe efectiva para a atacante que ocupa a posição de pivot e (ii) o papel defensivo fundamental da guarda-redes, o qual assume maior evidência quando garante a posse de bola através da antecipação de apoio à defesa central, nas intercepções relativamente ao passe dirigido à atacante pivot e, também, na execução do primeiro passe que ultrapasse o meio campo defensivo. Também se evidenciou o papel da defesa central aquando da anulação da atacante pivot ou na antecipação à mesma, na medida em que $11 \%$ da frequência das formas de recuperação da posse da bola dizem respeito à falta de ataque que habitualmente ocorre na área dos $2 \mathrm{~m}$ devido ao confronto intenso que se gera entre central e pivot na procura de uma melhor posição.

A preferência por um primeiro passe de alcance longo, efectuado para depois da linha central de meio campo, é reveladora quanto à transição defesa/ataque realizada pelas formações em estudo. Tal facto evita o dispêndio de tempo e o confronto físico que se verificaria se a transição fosse realizada através da circulação da bola no meio campo defensivo. Esta opção táctica obriga à recuperação defensiva das adversárias de forma passiva, procedendo à contenção no centro do campo, em virtude de a bola se encontrar avançada no terreno de jogo. Constatou-se, igualmente, que o corredor direito e o corredor central totalizam $75 \%$ da totalidade da recepção do primeiro passe, ou seja, só em $25 \%$ dos casos ocorre distribuição da bola pelo corredor esquerdo. Em conformidade, parece existir intencionalidade organizativa na transição defesa/ataque.

O número de jogadoras que participam directamente no processo ofensivo (4 e 5 jogadoras, incluindo a guarda-redes) sugere um jogo em profundidade, onde a circulação da bola e o tempo de realização do ataque é reduzido. As sequências desenvolvidas com um número de passes mais elevado sugerem a eleição preferencial da organização ofensiva com grande circulação da bola e com tempo 
de realização do ataque elevado, com situações de ataque posicional e desenvolvimento de situações de superioridade numérica.

Adicionalmente, os valores encontrados para a variável "número de variações de corredor" evidenciam o volume de circulação da bola pelo terreno de jogo, bem como do método de jogo ofensivo adoptado. Assim, quantas mais variações contemplar uma sequência ofensiva, maior será o nível organizacional da mesma, indicando que a equipa procura soluções ofensivas através da mudança de posição do móbil de jogo. Tal como Sarmento (1995) refere, variar a posição da bola relativamente à baliza, constitui um meio de provocar desadaptações na estrutura defensiva do adversário.

Quanto ao número de jogadoras envolvidas directamente no processo ofensivo (em média $4,3 \pm 1,4$ ), se for tomado em conta que na maioria das sequências ofensivas iniciadas sem que a formação tenha sofrido golo, a guarda-redes quase sempre tem intervenção directa na jogada, o número de jogadoras que evoluem no processo ofensivo e que nele intervêm directamente é, ainda, menor. De acordo com o observado, raramente as sete jogadoras têm intervenção directa no processo, o que não significa que a sua presença ou suas movimentações sejam menos determinantes para a construção do ataque. Distinguem-se, assim, a situação em que ocorre contra-ataque, sendo reduzido o número de jogadoras e a situação de ataque organizado, onde a jogadora pivot ocupa uma posição determinante. Nesta última situação, as possibilidades dividem-se em: (i) a bola é passada à pivot sendo interceptada ou conquistada pelas defesas por antecipação (nem todas as jogadoras intervêm directamente no processo); (ii) a bola é passada para a pivot, a qual finaliza ou obtém penalti (de igual forma, nem todas as jogadoras intervêm directamente no processo); (iii) a bola é passada à pivot e esta obtém uma superioridade numérica temporal (maiores possibilidades de intervenção de outras jogadoras); (iv) a atacante pivot não consegue receber a bola (nem todas as jogadoras intervêm directamente no processo). Das situações descritas, entendemos que a evolução do processo ofensivo dificilmente contempla as sete jogadoras, opinião concordante com os resultados obtidos.

Quanto aos métodos de jogo ofensivo utilizados pelas equipas com maior sucesso, constatou-se uma preferência clara pelo desenvolvimento do ataque posicional. Nos estudos de Lloret (1994) e Argudo (2000) verificou-se, igualmente, uma supremacia do desenvolvimento do ataque posicional em relação ao contraataque. Porém, no presente estudo, se à frequência de acções de contra-ataque adicionarmos a ocorrência do ataque rápido verifica-se que as sequências ofensivas 
de desfecho rápido, desenvolvidas pelas três formações, adquirem valores importantes. Assim, constatamos que a Eq3 foi a mais eficaz, tendo desenvolvido preferencialmente $\mathrm{o}$ ataque posicional através de movimentos de entrada e penetração pelo espaço defensivo adversário, bem como o contra-ataque e ataque rápido. A Eq3 assume-se, igualmente, como a que mais varia o passe (em termos de alcance), a que mais jogadoras envolve directamente no processo ofensivo (5), a que apresenta a menor amplitude de variação do tempo de realização do ataque e a que mais finaliza de forma espontânea.

Os resultados acima descritos parecem estar de acordo com a literatura no que concerne às necessidades de movimentação da equipa, no sentido de romper a estrutura defensiva adversária. Nesse sentido, Sarmento e Magalhães (1991) referem que a finalização se torna mais fácil quanto mais perto da baliza se realizar. Sarmento (1995) alega, também, que o ganho e o aproveitamento de trajectórias de penetração constitui um meio eficaz para provocar desadaptações na estrutura defensiva adversária. Estes requisitos parecem ter sido cumpridos pela Eq3, apesar de esta não ter sido a primeira classificada dos campeonatos. Saliente-se, ainda, que no que concerne à eficácia ofensiva, a prestação da Eq3 superou a das outras duas formações, até à fase dos quartos de final. Tal poderá dever-se à influência de constrangimentos de ordem psicológica que se afiguram decisivos em competições deste nível.

Do exposto ressalta a relevância de preconizar um modelo de jogo que contemple as acções identificadas como indutoras de sucesso dos jogadores e das equipas. Tal implica uma escolha criteriosa dos exercícios a considerar nas sessões de treino, bem como a adopção de estratégias de instrução e de exercitação eficazes no que concerne ao modelo de jogo elegido.

Para além disso, deve destacar-se a importância dos constrangimentos de âmbito psicológico já que os mesmos poderão tornar-se decisivos, nomeadamente no que respeita às circunstâncias a criar para conseguir operacionalizar o modelo de jogo. Como reporta Smith (2006), o treino mental é indispensável e quando este é conjugado com o treino físico, potencia elevados níveis de prestação). Em conclusão, salienta-se que o modelo de jogo ofensivo de elite parece caracterizarse pela aquisição e recuperação da posse da bola por antecipação e defesa da guarda-redes, pela utilização preferencial de um primeiro passe longo que permita uma rápida transição defesa /ataque, pela progressão da bola pelo corredor direito, pela organização preferencial das acções segundo o método de jogo posicional e eleição do remate directo como forma de finalização. A exploração dos dados 
14 | Caracterização da organização do processo ofensivo em pólo aquático feminino de elite

permitiu perfilar alguns indicadores que parecem estar associados à eficácia ofensiva dos jogadores e das equipas, nomeadamente no que respeita à organização e à finalização, a saber: (i) método de jogo ofensivo de contra-ataque; (ii) ataque posicional com movimentos de entrada, nomeadamente através de penetrações pelo espaço defensivo adversário e (iii) superioridade numérica desenvolvida com alterações no dispositivo inicial adoptado. De sublinhar, igualmente, meios tácticos de grupo como: (i) as desmarcações; (ii) os bloqueios ofensivos e (iii) a assistência da jogadora pivot para as colegas posicionadas no semicírculo ofensivo. Por último, as variações de corredor parecem também constituir meios eficazes para induzir ruptura na estrutura defensiva adversária.

\section{Bibliografia}

Adelino, J. (1987). A importância dos modelos no trabalho do treinador. Actas do III Seminário internacional de desportos colectivos. Espinho.

Argudo, F. (2000). Modelo de evaluación táctica en deportes de oposición con colaboración. Estudio práxico del Waterpolo. Dissertação de Doutoramento, Valência: Faculdade de Psicologia da Universidade de Valencia.

Argudo, F., \& García, F. (1996). Enseñanza de la táctica en el Waterpolo (I). Comunicaciones Técnicas, 1, 21-29.

Argudo, F., \& Lloret, M. (1998). Análisis de la acción de juego por unidades de competición en Waterpolo. Actas do IV seminario internacional de la actividad física y el deport, Jornada de estudios práxicos, Grup de'estudis praxiològics do INEFC. Barcelona: Instituto Nacional de Educación Física da Cataluña.

Bayer, C. (1994). O ensino dos desportos colectivos. Lisboa: Editora Dinalivro.

Bellack, A., Kliebard, H., Hyman, R. \& Smith (1966). The language of classroom. Teaches college. New York: Columbia University Press.

Canossa, S. (2001). Modelo de jogo ofensivo no pólo aquático feminino de elite: Caracterização da organização do processo ofensivo das selecções femininas de elite, no Campeonato Europeu de Sevilha - 1997. Dissertação de Mestrado,Porto: FCDEF-UP.

Canossa, S., Fernandes, R., Carmo, C., Andrade, A., \& Soares, S. (2007). Ensino Multidisciplinar em Natação: Reflexão metodológica e proposta de lista de verificação. Revista Motricidade, 4(3), 82-99.

Carreio, J. (1992). Análise do desempenho ofensivo da Selecção Nacional de Pólo Aquático Feminino, no $1^{\circ}$ Torneio Internacional de Portugal. Dissertação com vista à aprovação da disciplina de Metodologia do Treino. Lisboa: FMH-UTL.

Castelo, J. (1994). Modelo Técnico-Táctico do jogo. Lisboa: FMH-UTL.

Egaña, G. (2000). Observación y Análisis de la acción de juego en el tenis de individuales: Aportaciones del análisis secuencial y de las coordenadas polares. Revista Digital Efdeportes, 5(21), 1-2. Consultado em 18 Dez 2000, disponível em http://www.efdeportes. com/efd21a/tenis.htm 
Garganta, J. (1996). Modelação da dimensão táctica do jogo de Futebol. In J. Oliveira \& F. Tavares (Eds.), Estratégia e Táctica nos jogos desportivos colectivos (pp.63-82). Porto: FCDEF-UP.

Garganta, J. (1997). Modelação Táctica do Jogo de Futebol: Estudo da organização da fase ofensiva em equipas de alto rendimento. Dissertação de Doutoramento, Porto: FCDEFUP.

Gréhaigne, J.F. (1992). L'Organisation du jeu en football. Joinville-le-Pont: Édition Actio.

Lloret, M. (1994). Análisis de la Acción de juego en el Waterpolo durante la Olimpiada de Barcelona-92. Dissertação de Doutoramento, Barcelona: INEF da Cataluña.

Lloret, M. (1998). Waterpolo, Tecnica - Táctica-Estratégia. Madrid: Gymmos editora.

Lloret, M., \& Zarralanga, A. (1990). Waterpolo. Técnica. Táctica. Niveles de aprendizaje. Barcelona: Hispano Europea.

Lopes, J. (1985). Os elementos básicos do Pólo Aquático. Horizonte, II(8), 64-66.

Pinto, A., Carvalho, F. \& Saraiva, V. (1989). Proposta Metodológica para Determinação e Estudo das Condicionantes Técnico - Tácticas do jogo de Pólo Aquático. Observação - um meio de rentabilizar o processo de treino desportivo. Dissertação com vista à aprovação da disciplina de opção de Natação. Porto: ISEF-UP.

Pinto, J., \& Garganta, J. (1996). Contributo da modelação da competição e do treino para a evolução do nível de jogo no Futebol. In J. Oliveira \& F. Tavares (Eds.), Estratégia e táctica nos jogos desportivos colectivos (pp.83-94). Porto: FCDEF-UP.

Ribeiro, I. (2005). Programa 7-Formação de Recursos Humanos, FPN 2005. Actas do Sector de Formação, integrado no Plano de Actividades da Federação Portuguesa de Natação. Lisboa: FPN.

Sarmento, P. (1987). A estrutura defensiva do Pólo Aquático. Actas da disciplina de estudos práticos I. Porto: ISEF-UP.

Sarmento, J.P. (1989). Estudo histórico da introdução desenvolvimento e desaparecimento do Pólo aquático em Portugal no período compreendido entre 1907 e 1952. Lisboa: Antologia de Textos, Desporto e Sociedade.

Sarmento, P. (1991). Análise das acções ofensivas. Horizonte, VII(45), 88-91.

Sarmento, P., \& Magalhães, L. (1991). Determinação de coeficientes para a valorização da observação do ataque em Pólo Aquático. Natação, IV(14), 7-8.

Sarmento, P. (1994). O Jogo e o Jogador de Pólo Aquático Português. Dissertação de Doutoramento, Porto: FCDEF-UP.

Sarmento, P. (1995). O ensino do Pólo Aquático. In A. Graça \& J. Oliveira (Eds.), O ensino dos jogos desportivos (pp.201-218). Porto: FCDEF-UP.

Silva, A. (2000). A importância dos indicadores do jogo na discriminação da vitória e derrota em Andebol. Dissertação de Mestrado, Porto: FCDEF-UP.

Smith, K. (2006). The Other Half Of Peak Performance: Mental Training in Water Polo. USA Water Polo, Inc., 1-3. Consultado em 26 Out 2007, disponível em http://usawaterpolo.org/ 